\title{
Isolation, optimisation and gasoline biodegradation by lipopeptide-producing Bacillus subtilis SE1
}

\author{
Subuntith Nimrat ${ }^{\mathrm{a}, *}$, Somruetai Lookchan ${ }^{\mathrm{b}}$, Traimat Boonthai ${ }^{\mathrm{c}}$, Verapong Vuthiphandchai ${ }^{\mathrm{d}}$ \\ a Department of Microbiology and Environmental Science Program, Faculty of Science, \\ Burapha University, Chon Buri 20131 Thailand \\ b Department of Microbiology, Faculty of Science, Burapha University, Chon Buri 20131 Thailand \\ c Biological Science Program, Faculty of Science, Burapha University, Chon Buri 20131 Thailand \\ d Department of Aquatic Science, Faculty of Science, Burapha University, Chon Buri 20131 Thailand
}

*Corresponding author, e-mail: subunti@buu.ac.th

Received 1 Jul 2019

Accepted 30 Nov 2019

\begin{abstract}
Biosurfactant-producing bacteria were isolated from hydrocarbon contaminated soils. The highest surface and emulsification activities were achieved with a strain identified as Bacillus subtilis SE1. Optimal condition for biosurfactant production of $B$. subtilis SE1 included supplementation of glucose and yeast extract (10 g/l each) in the medium at $30^{\circ} \mathrm{C}$, initial $\mathrm{pH} 7.0$ and no $\mathrm{NaCl}$ added, giving biosurfactant yield of $66.00 \pm 1.54 \mathrm{mg} / \mathrm{l}$. Biosurfactant produced by $B$. subtilis SE1 was characterised as lipopeptide and reduced the surface tension from $72.27 \pm 0.01$ to $25.95 \pm 0.06 \mathrm{mN} / \mathrm{m}$ with a critical micelle concentration of $4.69 \pm 0.11 \mathrm{mg} / \mathrm{l}$. In a biodegradation assay, the experiment was conducted in 3 treatments for 7 days: gasoline-contaminated soil (T1); gasoline-contaminated soil with B. subtilis SE1 bioaugmentation (T2); and gasoline-contaminated soil with addition of B. subtilis SE1 and nutrients (glucose and yeast extract) (T3). The highest viable bacterial count $(8.00 \pm 0.04 \log \mathrm{CFU} / \mathrm{g})$ and percent reduction of total phenolic content $(9.73 \pm 1.13 \%)$ were observed in T3, which were significantly $(p<0.05)$ higher than those of T1 (5.60 $\pm 0.02 \mathrm{log} \mathrm{CFU} / \mathrm{g}$ and 3.68 $\pm 0.83 \%)$ and T2 (7.12 $\pm 0.01 \mathrm{log} \mathrm{CFU} / \mathrm{g}$ and $5.04 \pm 0.30 \%)$. These results reveal the potential of biosurfactant-producing $B$. subtilis SE1 for use in bioremediation of hydrocarbon contaminated environment in Thailand.
\end{abstract}

KEYWORDS: Bacillus subtilis, lipopeptide, biosurfactant, gasoline, biodegradation

\section{INTRODUCTION}

Petroleum and petrochemical products are one of the most common hazardous chemicals involved in environmental pollution. Gasoline is a refined petrochemical product comprising a mixture of benzene, toluene, ethylbenzene and xylene isomers, compounds usually termed BTEX. These compounds are thought to be one of the most prevalent contaminants in soils, drinking water and groundwater through accidental spillages and leakages in aboveground and underground storage tanks and pipelines as well as improper waste disposal practices [1]. Hydrocarbon spills directly damage natural ecosystems, indirectly have an economic impact $[2,3]$ and increase the presence of hazardous chemicals which can bioaccumulate, biomagnify and eventually cause serious human health effects [4]. The International Agency for Research on Cancer (IARC) categorises gasoline as possibly carcinogenic to humans (group 2B) [5]. Among the compositions of gasoline, IARC classifies benzene as group 1 (carcinogenic to humans), ethylbenzene as group 2B and toluene and xylene as group 3 (not classifiable as to its carcinogenicity to humans) [6].

Sustainable management is a challenging concept circumscribing how intersection among society, economy and environment can be connected properly. Several techniques have been used to clean up the environment from hazardous petrochemicals. Among all approaches applied, bioremediation, a natural method whereby microorganisms breakdown, reduce, eliminate or transform organic molecules to benign compounds, is considered a good strategy to remove hydrocarbon contaminants and remediate the environment in a short period of time because of its environmentally-friendly, costeffective and efficient technique [3]. However, due to biodegradation being hampered by limited bioavailability of hydrophobic pollutants, biosurfactants are needed to be added into contaminated ecosystems. 
Members of the Bacillus genus have considerably gained attraction because of their ability to secrete a broad spectrum of biologically active molecules. Lipopeptides are among the most commonly isolated and characterised biosurfactants produced by Bacillus species. They are considered safe, ecologically-acceptable, biodegradable and low toxic and represent higher selectivity than chemically synthetic counterparts which are often toxic, may leave undesirable residues and constitute an additional source of contamination [7]. Some lipopeptide biosurfactants show activity even at extreme temperature, $\mathrm{pH}$ and salinity [8]. Despite lipopeptides from Bacillus species found to substantially enhance degradation efficiency of several hydrocarbons and petrochemical products, there are a few studies reported specifically the role of lipopeptides on gasoline bioremediation, but most study focused on degradation potential of its major aromatic volatile constitutes such as benzene, toluene, and xylenes by Bacillus species [9]. Lipopeptides have been reported to play a role in improving accessibility, mobility and bioavailability of the water immiscible petrochemicals, thereby allowing them to mix readily as emulsions in water leading to enhanced bacterial growth and increased rate of biodegradation [10]. Isolation and characterisation of lipopeptide-producing Bacillus to remediate gasoline-contaminated environments have received very little attention in Thailand.

Several species of lipopeptide-producing Bacillus have been widely isolated from a variety of petroleum-polluted environments and confirmed for their application potential in the bioremediation of oil-contaminated sites and microbial enhanced oil recovery process $[8,11]$. In order to obtain high production of surface active substances and promote the growth of Bacillus isolate, optimisation of the important parameters e.g., carbon and nitrogen sources, $\mathrm{pH}$, temperature and salinity is substantially needed. It is worth noting that type of growthlimiting nutrients is considerably important for production of bacterial bioactive molecules. Carbon source has been proven to affect quantity, structure and activity of biosurfactants $[8,12]$. A similar consequence was also reported when biosurfactantproducing Bacillus spp. grew in different nitrogen source, temperature, $\mathrm{pH}$ and salinity $[8,12-14]$. Therefore, the purposes of this study were to (1) isolate biosurfactant-producing bacteria from petrochemical contaminated soils, (2) improve lipopeptide biosurfactant production of a Bacillus isolate through optimisation of the carbon and nitrogen sources in the culture medium together with environmental factors and (3) evaluate the feasibility of the lipopeptide-producing bacterium isolated for its use in biodegradation of gasoline contaminated soil.

\section{MATERIALS AND METHODS}

\section{Soil collection}

Petroleum contaminated soils were collected from various sites in Chon Buri province, Thailand: Bang Sean Beach (SA), Naklue Pattaya Beach (SN), Jomtein Pattaya Beach (SJ) and a local automobile garage (SO). At each sampling site, samples were collected at depth of $0-10 \mathrm{~cm}$ using a hand trowel [15]. Samples were kept in an icebox and transported to the laboratory for further analysis.

\section{Isolation and enrichment of biosurfactant producing bacteria}

Oil degrading bacteria were isolated from samples using a spread plate method. All samples $(10 \mathrm{~g})$ from several sites were 10 -fold diluted with $0.85 \%(\mathrm{w} / \mathrm{v}) \mathrm{NaCl}$ solution, and $0.1 \mathrm{ml}$ of each dilution was plated onto Plate Count Agar (Difco). All Petri dishes were incubated at $35^{\circ} \mathrm{C}$ for 24-48 h [15]. Moreover, an enrichment technique was used following a method of Howland and Garfield [16]. Sealed bottle containing gasolinesoaked soil samples (10.5 g) collected from a local automobile garage was amended with $10 \mathrm{ml} / \mathrm{kg}$ final concentration of gasoline and incubated at $35^{\circ} \mathrm{C}$ for 7 days prior to isolating the bacteria as described above. This enriched soil sample was designated as SE. All morphologically distinct colonies were streaked on Trypticase Soy Agar (TSA; Difco) to obtain pure cultures and then screened for biosurfactant production.

\section{Screening for biosurfactant producers}

Bacterial isolates were cultured in $250 \mathrm{ml}$ flasks containing $50 \mathrm{ml}$ medium broth composed of $(\mathrm{g} / \mathrm{l})$ peptone (10), beef extract (10) and $\mathrm{NaCl}$ (5) in a shaking incubator at $180 \mathrm{rpm}, 30^{\circ} \mathrm{C}$ for $72 \mathrm{~h}$. After centrifuging at $7713 \times \mathrm{g}, 4^{\circ} \mathrm{C}$ for $30 \mathrm{~min}$, cellfree supernatants were collected and subjected to various screening assays to test for biosurfactant production. Two preliminary screening techniques including drop collapsing and oil displacement tests were carried out using gasoline following published methods [11]. Emulsification activity of the cellfree supernatants was also measured according to the method described by Cooper and Goldberg [17]. All screening tests were performed in 4 replicates. 
Sterile distilled water and $10 \mathrm{~g} / \mathrm{l}$ sodium dodecyl sulfate were used as negative and positive controls, respectively.

\section{Growth and biodegradation potential towards gasoline of B. subtilis SE1}

Growth and biodegradation potential of SE1 isolate were studied using Mineral Salt Medium (MSM) following the method by Dagorn et al [18] with some modifications. The MSM consisted of $(\mathrm{g} / \mathrm{l}) \quad \mathrm{Na}_{2} \mathrm{HPO}_{4}$ (3.6), $\left(\mathrm{NH}_{4}\right)_{2} \mathrm{SO}_{4} \quad$ (1.0), $\mathrm{KH}_{2} \mathrm{PO}_{4}$ (1.0), $\mathrm{MgSO}_{4}$ (1.0), $\mathrm{Fe}\left(\mathrm{NH}_{4}\right)_{3}\left(\mathrm{C}_{6} \mathrm{H}_{5} \mathrm{O}_{7}\right)_{2}$ (0.01) and $\mathrm{CaCl}_{2} \cdot 2 \mathrm{H}_{2} \mathrm{O}(0.1)$ and $10 \mathrm{ml}$ of trace element solution (mg/l): $\mathrm{ZnSO}_{4} \cdot 7 \mathrm{H}_{2} \mathrm{O}$ (10.0); $\mathrm{MnCl}_{2} \cdot 4 \mathrm{H}_{2} \mathrm{O}$ (3.0); $\mathrm{CoCl}_{2} \cdot 6 \mathrm{H}_{2} \mathrm{O}$ (1.0); $\mathrm{NiCl}_{2} \cdot 6 \mathrm{H}_{2} \mathrm{O}(2.0) ; \mathrm{Na}_{2} \mathrm{MoO}_{4} \cdot 2 \mathrm{H}_{2} \mathrm{O}(3.0) ; \mathrm{H}_{3} \mathrm{BO}_{3}$ (30.0) and $\mathrm{CuSO}_{4} \cdot 2 \mathrm{H}_{2} \mathrm{O}$ (1.0). A 24-h old SE1 culture grown in the medium broth was adjusted to $1.5 \mathrm{AU}$ at $580 \mathrm{~nm}$ equivalent to $10^{10} \mathrm{CFU} / \mathrm{ml}$ of cell concentration using a spectrophotometer. The SE1 suspension $(10 \mathrm{ml})$ was loaded into a $180-\mathrm{ml}$ bottle with silicone rubber stoppers containing $89 \mathrm{ml}$ of MSM. The bottles with SE1 suspension were divided to 2 batches: active and sterile (autoclaved SE1 culture) groups. A small volume (1 ml) of gasoline was added into all serum bottles. Serum bottles with the sterile medium instead of SE1 suspension was considered background group. During a 35-d incubation at $30^{\circ} \mathrm{C}, 200 \mathrm{rpm}$, cultivation broth was collected to monitor the cell growth by measuring $\mathrm{OD}_{580}$. After centrifuging at $8228 \times g$, $4^{\circ} \mathrm{C}$ for $5 \mathrm{~min}$, an additional cell-free supernatant was scanned at wavelength between 220 and $400 \mathrm{~nm}$ using a UV-visible spectrophotometer. All experiments were achieved in triplicate.

\section{Identification of biosurfactant-producing strain and phylogenetic analysis}

Of all isolates, SE1 strain was capable of employing gasoline as sole carbon source and exhibited the highest surface and emulsification activities towards gasoline. Therefore, this strain was subjected to $16 \mathrm{~S}$ rRNA gene sequencing analysis for species identification. Genomic DNA was extracted from purified SE1 strain using a phenol-chloroform extraction method [19]. The primers fd1: 5' AGAGTTTGATCCTGGCT CAG $3^{\prime}$ and rP2: $5^{\prime}$ ACGGCTACCTTGTTACGACTT $3^{\prime}$ were used in this study. PCR reaction was composed of $1 \mathrm{X}$ reaction buffer $(10 \mathrm{mM}$ Tris$\mathrm{HCl} \mathrm{pH} \mathrm{9.1,} 50 \mathrm{mM} \mathrm{KCl}), 2.5 \mathrm{mM} \mathrm{MgCl}{ }_{2}, 100 \mu \mathrm{M}$ of each dNTPs, $0.64 \mu \mathrm{M}$ of each primer, $1.25 \mathrm{U}$ Taq DNA Polymerase, $20 \mathrm{ng}$ of DNA template and DNAase-free water to produce a final volume of
$50 \mu 1$. Amplification was performed in a PCR Thermal cycler (Biometra T-Gradient) with the following program: $95^{\circ} \mathrm{C}$ for $5 \mathrm{~min}$; 40 cycles of $95^{\circ} \mathrm{C}$ for $1 \mathrm{~min}, 55^{\circ} \mathrm{C}$ for $1 \mathrm{~min}$ and $72^{\circ} \mathrm{C}$ for $1 \mathrm{~min}$ each, and final elongation at $72^{\circ} \mathrm{C}$ for $7 \mathrm{~min}$. The sequence was compared to the 16S rRNA nucleotide sequences at National Center for Biotechnology Information (NCBI; www.ncbi.nlm.nih.gov) using the blastn algorithm.

The 16S rRNA gene sequences of closely related strains were ClustalW aligned in Molecular Evolutionary Genetics Analysis software (MEGA version 7). Evolutionary distance was calculated with the Tamura 3-parameter model. Neighbour-joining analysis was constructed using the MEGA version 7 , and topology robustness was assessed via bootstrap analysis of 1000 replicates.

\section{Thin layer chromatography (TLC)}

The cell-free supernatant was subjected to acid precipitation by adding $6 \mathrm{~N} \mathrm{HCl}$ to a final $\mathrm{pH} 2.0$ and allowing to settle at $4{ }^{\circ} \mathrm{C}$ overnight. The acid precipitate was collected and dissolved in methanol. Methanolic extract was spotted on a TLC plate (silica gel 60 plate; Merck KGaA). After transferring into a chamber containing mobile phase of chloroform:methanol:water $(65: 25: 4)$, the developed TLC plate was removed and allowed to air dry. The TLC plate was sprayed with ninhydrin solution $(0.25 \% \mathrm{w} / \mathrm{v}$ in ethanol) for presence of peptide moiety and treated with water to detect lipid moiety [20].

\section{Optimisation of physicochemical factors for biosurfactant production of SE1 strain}

Optimisation study was performed in a stepwise fashion by changing one variable at a time and keeping other factors fixed at a specific set of conditions. The first factor studied was carbon source, followed by nitrogen source, $\mathrm{pH}$, temperature and salinity, respectively. Biosurfactant production was evaluated using MSM with different carbon and nitrogen sources. Three carbon source (glucose, glycerol and palm oil) treatments were analysed at a final concentration of $10 \mathrm{~g} / \mathrm{l}$. Three nitrogen sources: sodium nitrate, urea and yeast extract were added to produce a final concentration of $10 \mathrm{~g} / \mathrm{l}$ in MSM medium, and glucose was used as sole carbon source. To study $\mathrm{pH}$ effect on biosurfactant production, $\mathrm{pH}$ of the MSM medium was adjusted to $5,6,7,8$ and 9 . The temperature effect was assessed by incubating the culture at 25, 30, 37 and $45^{\circ} \mathrm{C}$. Finally, the MSM medium was prepared with 
supplementation of sodium chloride at $0,10,20,30$, 55,100 and $150 \mathrm{~g} / 1$ to study salinity impact.

Cultivation assays were carried out in $250 \mathrm{ml}$ flasks containing $50 \mathrm{ml}$ of the different media. Each flask was inoculated with $1 \%(\mathrm{v} / \mathrm{v})$ of 24 -h old SE1 culture. After agitation in an incubator shaker at $180 \mathrm{rpm}$ for 3 days, cell suspensions were centrifuged at $7713 \times \mathrm{g}, 4^{\circ} \mathrm{C}$ for $30 \mathrm{~min}$. Afterwards, cell-free supernatants were used to measure surface activity using an oil displacement technique. At the end of optimisation study, cell-free supernatant collected from SE1 strain cultured at optimal conditions was evaluated for its surface tension and biosurfactant concentration. The optimisation assay was done in three independent replicates.

\section{Biosurfactant quantification}

Lipopeptide was extracted from cell-free supernatant using acid precipitation and dissolved in methanol as mentioned previously. Lipopeptide was analysed and quantified by reversed-phase High Performance Liquid Chromatography (HPLC; Shimadzu, Model Shimadzu LC-10) [21]. The methanolic extract was characterised using an inersil ODS-C18 column ( $5 \mu \mathrm{m}, 250 \mathrm{~mm} \times 4.6 \mathrm{~mm}$ ). Surfactin solution (Sigma-Aldrich) was used as a reference substance.

\section{Surface tension}

Surface tension measurement of culture supernatant was achieved following the Du Nouy Ring method [22] using a digital surface tensiometer (Kyowa Interface Science, Model DY-300) at $25^{\circ} \mathrm{C}$. The concentration at which micelles started to form was expressed as critical micelle concentration (CMC) value.

\section{Bacterial dynamics and metabolite fate during biodegradation in gasoline-contaminated soils \\ Soil microcosm experiment}

The potential use of biosurfactant producing SE1 strain for biodegradation of gasoline was assessed using artificially contaminated soil following Okoh method [23] with some modifications. A loamy sand soil was collected from Bang Sean Beach, Chon Buri, Thailand. Soil sample (300 g) was artificially amended with $1 \%(\mathrm{v} / \mathrm{w})$ gasoline and thoroughly mixed in a $500 \mathrm{ml}$ Erlenmeyer flask. Biodegradation experiment was conducted in 3 different treatments as follows: gasoline-contaminated soil (T1); gasoline-contaminated soil with SE1 bioaugmentation (T2); and gasoline-contaminated soil with addition of SE1 and nutrients (glucose and yeast extract $(1 \% \mathrm{w} / \mathrm{w}$ each) (T3). Aliquot $(1 \mathrm{ml})$ of SE1 suspension $\left(10^{9} \mathrm{CFU} / \mathrm{ml}\right)$ grown in glucose/YEamended MSM medium was inoculated into the soils of the 3 treatments. The experiment was performed in triplicate. During static incubation at $30^{\circ} \mathrm{C}$ in the dark, soil samples were withdrawn from each flask at $2 \mathrm{~h}, 3$ and 7 day post-inoculation for viable bacteria count and metabolite analysis. Aliquots of appropriate dilutions were spread-plated in triplicate onto Plate Count Agar for bacterial enumeration. After incubation at $30^{\circ} \mathrm{C}$ for $24 \mathrm{~h}$, all bacterial colonies grown on the medium were counted and expressed as log colony forming unit/g. The survival of SE1 strain was confirmed by biochemical tests compared to original isolate and polymerase chain reaction.

\section{Determination of metabolites}

The presence of phenolic intermediates in experimentally contaminated soils was investigated using a modified Folin-Ciocalteu (FC) reaction [24]. Briefly, $0.1 \mathrm{ml}$ of sample solution was mixed with $20 \%(\mathrm{w} / \mathrm{v}) \mathrm{Na}_{2} \mathrm{CO}_{3}(1.5 \mathrm{ml}), \mathrm{FC}$ reagent $(0.5 \mathrm{ml})$ and distilled water $(7.9 \mathrm{ml})$ in a volumetric flask. After incubation in the dark for $3 \mathrm{~h}$, reaction mixtures were measured at $765 \mathrm{~nm}$ using a spectrophotometer. Concentration of total phenolic content was quantified as gallic acid equivalent from the standard curve of gallic acid and calculated as percent reduction of total phenolic content (PRP), $\mathrm{PRP}$ value $(\%)=\left(\mathrm{PC}_{\mathrm{i}}-\mathrm{PC}_{\mathrm{x}}\right) / \mathrm{PC}_{\mathrm{i}} \times 100$, where $\mathrm{PC}_{\mathrm{i}}=$ initial concentration of total phenolic content and $\mathrm{PC}_{\mathrm{x}}=$ concentration of total phenolic content at day $\mathrm{x}$.

\section{Statistical analysis}

Data were expressed as mean \pm SD. Data were normalised and transformed when needed. Differences were determined using ANOVA, followed by Duncan's multiple range test at a significant level of $p<$ 0.05 [25]. All statistical analyses were performed using SPSS version 19.0, Chicago, Illinois, USA.

\section{RESULTS AND DISCUSSION}

\section{Biosurfactant producers and identification}

Of all isolates screened, 2 isolates (SE1 and SN1) were positive for drop collapsing test and represented the highest halo zone (ca. $33.7 \mathrm{~mm}$ ) of oil displacement activity (Table 1). A complementary assessment of biosurfactant performed in this study was measurement of emulsification activity. SE1 
Table 1 Emulsification activities of cell-free supernatants obtained from some bacterial isolates from petroleum contaminated soils in Chon Buri province, Thailand.

\begin{tabular}{lccc}
\hline $\begin{array}{l}\text { Bacterial } \\
\text { isolates }\end{array}$ & $\begin{array}{c}\text { Drop } \\
\text { collapsing } \\
\text { test }\end{array}$ & $\begin{array}{c}\text { Oil } \\
\text { displacement } \\
(\mathrm{mm})\end{array}$ & $\begin{array}{c}\text { Emulsification } \\
\text { capacity } \\
\left(\% \mathrm{E}_{24}\right)\end{array}$ \\
\hline SA1 & + & $9.0 \pm 2.0$ & $0.0 \pm 0.0$ \\
SO1 & + & $0.0 \pm 0.0$ & $15.6 \pm 0.0$ \\
SO3 & - & $4.0 \pm 1.4$ & $36.8 \pm 4.2$ \\
SE1 & + & $33.7 \pm 4.6$ & $70.2 \pm 1.5$ \\
SE2 & + & $10.7 \pm 0.6$ & $51.2 \pm 14.6$ \\
SE3 & + & $23.7 \pm 2.1$ & $14.4 \pm 4.9$ \\
SN1 & + & $33.7 \pm 2.1$ & $13.5 \pm 1.8$ \\
SJ1\#1 & + & $13.3 \pm 2.1$ & $63.2 \pm 6.0$ \\
SJ2\#1 & + & $7.7 \pm 1.5$ & $11.7 \pm 2.9$ \\
SJ2\#2 & - & $5.7 \pm 0.6$ & $10.9 \pm 4.7$ \\
SJ2\#3 & + & $23.7 \pm 2.1$ & $0.0 \pm 0.0$ \\
\hline
\end{tabular}

isolate showed the strongest emulsification activity supported by its ability to emulsify gasoline with $\mathrm{E}_{24}$ of $70.2 \pm 1.5 \%$ (Table 1). Our results claimed that drop collapsing and oil displacement assays were strongly recommended for primary screening of biosurfactant producers. Similar results were reported by Thavasi et al [26] who recommended these 2 assays as reliable primary methods to screen a number of potential biosurfactant producers.

\section{Growth and biodegradation potential towards gasoline of B. subtilis SE1}

Growth of bacteria in petroleum hydrocarbon medium is an important criterion to determine the biodegradation success of hydrophobic compounds in polluted systems. Cell density of active SE1 strain in gasoline-added MSM increased progressively from $0.34 \pm 0.01$ to $0.47 \pm 0.01$ during first 14 days of incubation and thereafter rapidly increased to $0.72 \pm 0.02$ at 35 -d post incubation (Fig. 1a), indicating a bacterial growth. Multiple peaks of a plenty of hydrocarbon substances in gasoline were observed in MSM containing sterile $B$. subtilis SE1 throughout a 35-d incubation (Fig. 1b). In contrast, absorption peaks of spectrographic compositions progressively decreased with an increase in incubation period. There was only one main component at approximately $262 \mathrm{~nm}$ after 14-d post incubation (Fig. 1c) and the main composition was absent at 35 days of incubation (Fig. 1d). This indicated removal of gasoline by biological activity. Our results were similar to a study conducted by Liu et al [27]. They observed that Bacillus isolates: Bacillus sp. L4, N3 and N6, were efficient degraders of benzene, a major component in gasoline, in the culture broth microcosm. Likewise, B. subtilis strain MO5 had the degradation potential of BTEX in liquid culture together with the presence of oxygenase genes involved in BTEX degradation [28]. Mukherjee and Bordoloi [9] also reported that lipopeptide-producing $B$. subtilis DM04 was capable of employing BTX as sole carbon and energy sources evidenced by an increased biomass simultaneously with an increased degradation percentage of the aromatic substances. The growth of SE1 strain in this study may be associated with utilisation of hydrocarbon components in gasoline supported by changing in absorption profile during a 35-d incubation. Appearance and disappearance of new absorption peaks detectable at wavelength between 220 and $400 \mathrm{~nm}$ was possibly due to degradation of the hydrocarbon compounds and/or formation of metabolites in the culture broth through functions of multiple enzymes e.g., benzene dioxygenase, toluene dioxygenase and xylene monoxygenase [28]. Expression of these oxidoreductase enzymes in SE1 strain is under current investigation.

SE1 strain was a potential producer of surfaceactive molecules and selected for further characterisation and study. SE1 isolate was recovered from gasoline-enriched soil sample due to its ability to utilise the gasoline components. It is noted that during enriching period, bacteria with active enzyme systems for hydrocarbon metabolism can adapt to grow with hydrophobic compounds as sole carbon source [2]. The 16S rRNA sequence analysis revealed that $B$. subtilis SE1 shared $99.93 \%$ homology with $B$. subtilis subsp. subtilis $\mathrm{NCIB} 610^{\mathrm{T}}$ (accession no. ABQL01000001). The nucleotide sequence of $B$. subtilis SE1 was deposited in the GenBank database (accession no. MH700588). In Fig. 2, $B$. subtilis SE1 was placed within the well-supported clade composed of $B$. subtilis and B. tequilensis reference sequences. Several authors confirm that Bacillus have a promising potential for biosurfactant production $[2,8,11]$. A member of $B$. subtilis group was reported to synthesise biosurfactants with a high emulsification index: viz. B. subtilis $\mathrm{CN} 1$ and B. subtilis $\mathrm{B} 30[11,29]$. In accordance with Zhang et al [8], biosurfactant produced by B. atrophaeus 52a had a high emulsifying activity in range of 54.11$61.81 \%$ when growing in the medium containing different carbon sources (glucose, glycerol, starch, sucrose, maltose and mannitol). 

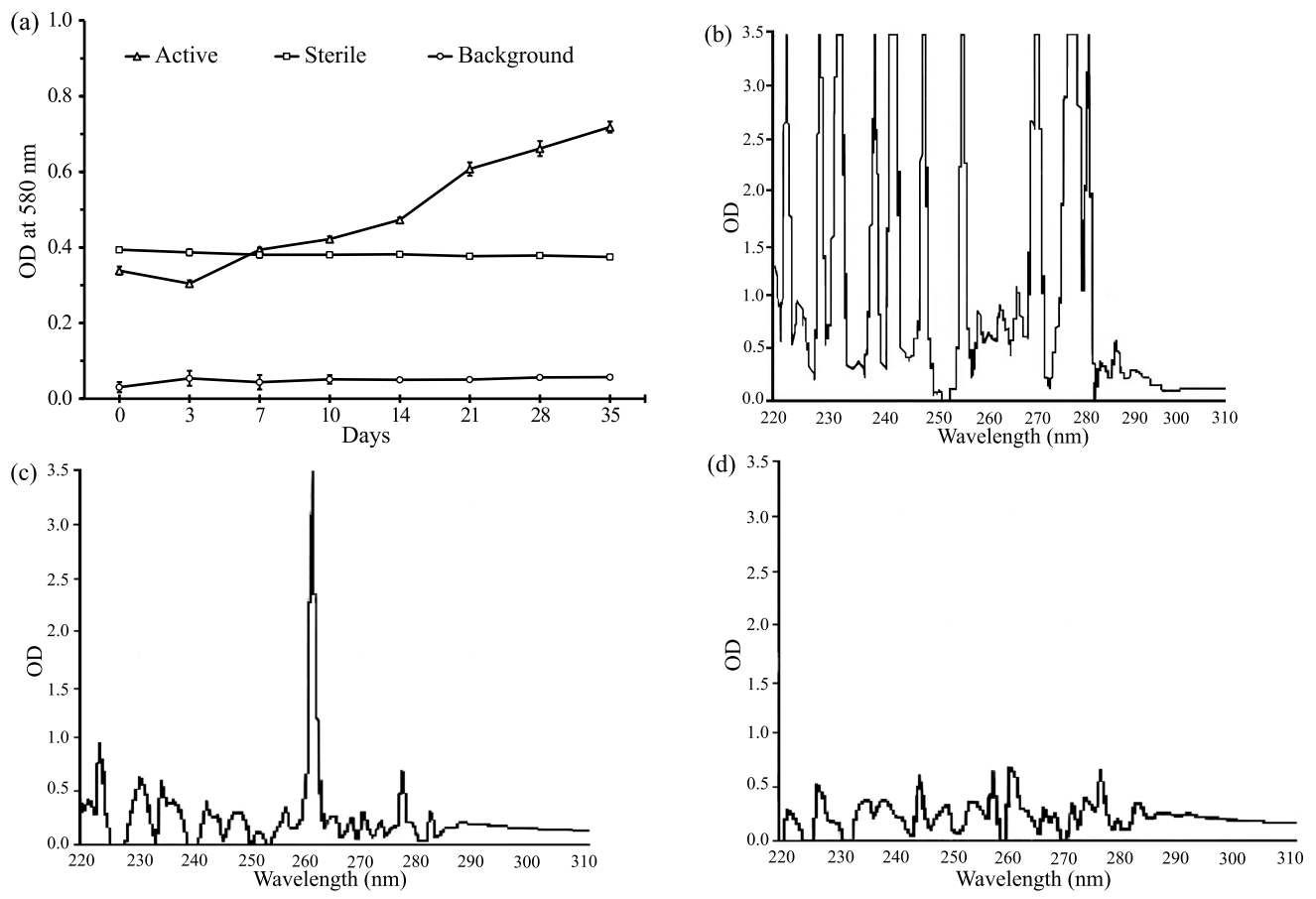

Fig. 1 (a) Cell growth kinetics towards gasoline of B. subtilis SE1 in Mineral Salt Medium during a 35-day incubation period, (b) absorption profile of gasoline biodegradation in the culture broth seeded with sterile B. subtilis SE1 at 35 days post-incubation and active B. subtilis SE1 at (c) 14 and (d) 35 days post-incubation.

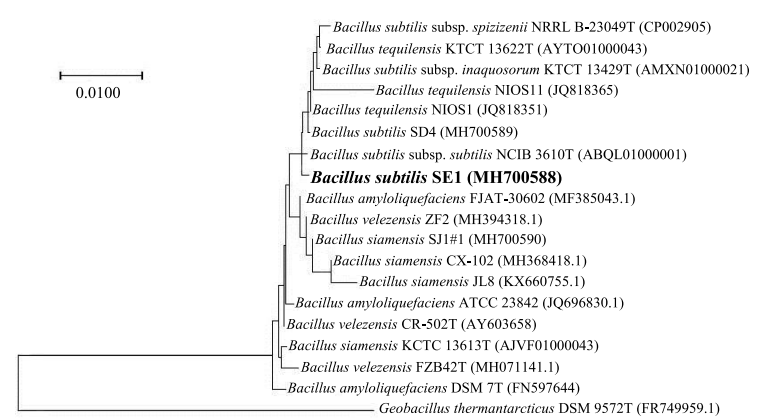

Fig. 2 Neighbour-joining phylogenetic tree of 16S rRNA gene sequences demonstrating the phylogenetic position of $B$. subtilis SE1. Only bootstrap values $\geqslant 50$ (1000 replicates) are displayed at the nodes. Scale-bar means number of substitutions per nucleotide site. Number in bracket indicates accession number.

Effect of carbon and nitrogen sources and environmental factors on oil displacement activity

It is widely known that composition and yield of biosurfactant produced by Bacillus species are dependent primarily on sources of carbon and nitrogen, $\mathrm{pH}$, temperature and salinity $[8,13,14,30]$. In this study, the diameter based on oil displacement test of biosurfactant varied depending on the carbon source supplied. Supernatant from B. subtilis SE1 grown in MSM containing glucose $(10 \mathrm{~g} / \mathrm{l})$ as carbon source produced the best oil displacement activity of $7.33 \pm 0.29 \mathrm{~cm} / 20 \mu \mathrm{l}$ while glycerol gave the least activity of $2.50 \pm 0.00 \mathrm{~cm} / 20 \mu \mathrm{l}$ (Fig. 3a). Glucose was found to be the most preferred carbon source for biosurfactant production of Bacillus isolates [29,31]. However, Bacillus strains were also reported to effectively biosynthesise surface-active molecules when growing in medium containing glycerol or palm oil as a sole carbon source $[8,12]$.

In general, organic substrates (e.g., yeast extract, beef extract, tryptone and peptone) and inorganic compounds (e.g., urea, ammonium sulfate, ammonium chloride, sodium nitrate and ammonium acetate) can be used for biosurfactant production. The best nitrogen source for lipopeptide SE1 production was yeast extract $(10 \mathrm{~g} / 1)$, showing oil displacement activity of $7.30 \pm 0.40 \mathrm{~cm} / 20 \mu \mathrm{l}$ (Fig. 3b). Parthipan et al [30] observed that maximum production of biosurfactant produced by B. subtilis A1 was achieved in a scenario where the medium contained yeast extract. In our study, a significant $(p<0.05)$ increase in oil displacement activity of $6.00 \pm 0.00 \mathrm{~cm} / 20 \mu \mathrm{l}$ was also 

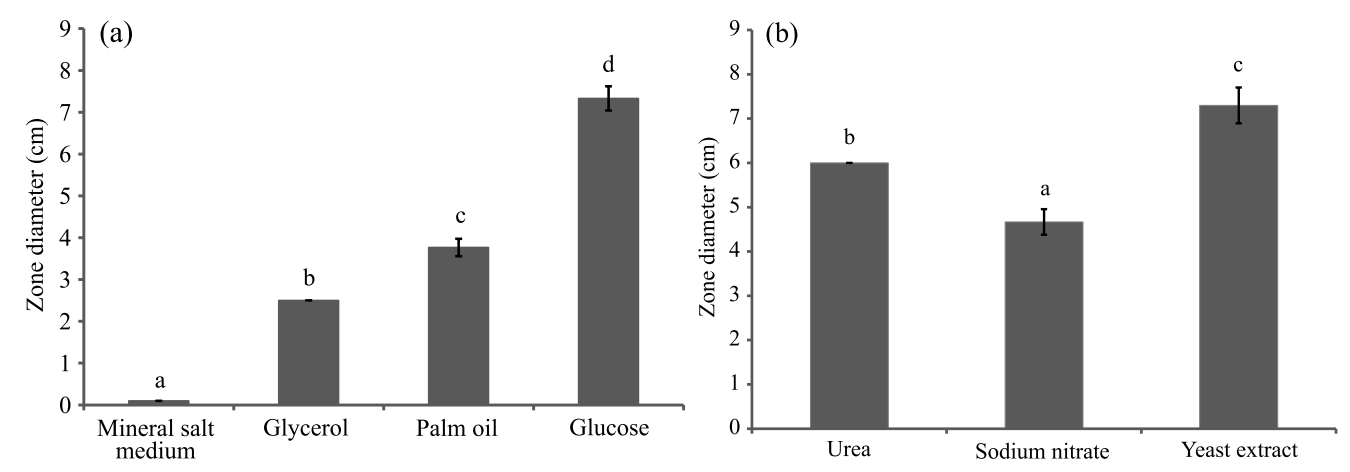

Fig. 3 Oil displacement activity of lipopeptide biosurfactant produced by B. subtilis SE1 grown in the medium containing different (a) carbon and (b) nitrogen sources. Letters indicate significant difference $(p<0.05)$ among treatments.

observed when urea was included in the MSM, compared to sodium nitrate $(4.67 \pm 0.29 \mathrm{~cm} / 20 \mu \mathrm{l}$; Fig. 3b). These results corroborated with the study by Zhang et al [8] reporting the biggest diameter of oil displacement produced from a lipopeptide biosurfactant when B. atrophaeus 5-2a cultured in the medium supplied with urea as nitrogen source. Ghribi and Ellouze-Chaabouni [31] also reported that the amount of biosurfactant produced by $B$. subtilis SPB1 was greater when urea was supplied in growth medium. B. subtilis SE1 utilising urea in preference to sodium nitrate may be explained by the metabolism activity. Urea is not involved directly in protein synthesis, but it can be cleaved by enzymatic activity to liberate ammonium, which is more available for biosynthesis [13]. Davis et al [32] revealed that biosurfactant producing $B$. subtilis ATCC 21332 utilised nitrate when ammonium was depleted in the medium.

Surface activity of biosurfactant from strain SE1 grown in different $\mathrm{pH}$ medium was illustrated in Fig. 4a. Culturing B. subtilis SE1 in MSM at $\mathrm{pH} 7.0$ was the best condition for biosurfactant production due to displaying oil displacement activity of $11.77 \pm 0.70 \mathrm{~cm} / 20 \mu \mathrm{l}$. When $B$. subtilis SE1 grew under alkaline condition at $\mathrm{pH} 8.0$ and 9.0 , the activity significantly $(p<0.05)$ reduced to $5.90 \pm 0.53$ and $4.53 \pm 0.06 \mathrm{~cm} / 20 \mu \mathrm{l}$, respectively (Fig. 4a). Several authors have exhibited that Bacillus spp. well proliferate and produce surface-active molecules at broad $\mathrm{pH}$ range (4-10), but $\mathrm{pH} 7.0$ was an optimal incubation condition for biosurfactant production $[13,20,30]$.

The maximum oil displacement activity of $12.37 \pm 0.32 \mathrm{~cm} / 20 \mu \mathrm{l}$ was reached when $B$. subtilis SE1 inoculated MSM was incubated at $30^{\circ} \mathrm{C}$. Incubation of $B$. subtilis SE1 at 25 and $37^{\circ} \mathrm{C}$ produced significant reduction in oil displacement activity of $7.23 \pm 0.25$ and $6.00 \pm 0.30 \mathrm{~cm} / 20 \mu \mathrm{l}$, respectively. When the culture was incubated at $45^{\circ} \mathrm{C}$, the subsequent activity was extremely reduced to $3.30 \pm 0.00 \mathrm{~cm} / 20 \mu \mathrm{l}$ (Fig. 4b). Our results were similar to other studies reporting $30^{\circ} \mathrm{C}$ as the best temperature for production of biosurfactants with high surface and emulsification activities of Bacillus isolates [13,20]. In addition, Bacillus strains were reported to have optimal temperature in the ranges of $25-45^{\circ} \mathrm{C}$ for biosurfactant production dependent on their species, habitats and environments [14, $30,33]$. Ohno et al [33] suggested that enzymes associated with metabolic pathway of biosurfactant synthesis were affected by the temperatures. In addition, they postulated temperature effect on lipopeptide activity through synthetic pathways of fatty-acid side chain at a lipid bilayer membrane of cells. The fatty acid composition of plasma membranes is normally altered following the temperature growth to maintain membrane integrity at a particular temperature.

Similar to the $\mathrm{pH}$ and temperature, salinity plays a key role in biosurfactant production. In this study, the greatest oil displacement activity of $12.83 \pm 0.76 \mathrm{~cm} / 20 \mu \mathrm{l}$ was achieved in MSM without $\mathrm{NaCl}$ addition (Fig. 4c). The activity was significantly $(p<0.05)$ decreased with increase in $\mathrm{NaCl}$ concentration. Growth and biosurfactant production of Bacillus strains in saline environment are variable. According to Tabatabaee et al [34], production of surface-active compounds of Bacillus sp. was optimal at $\mathrm{NaCl}$ concentration ranging from $1-5 \%$. Jha et al [14] isolated B. subtilis R1 from a petroleum-contaminated desert site and observed high salt tolerance of lipopeptide production up to $7 \%$ salt.

Activities of biosurfactants produced by different bacteria are generally influenced by sub- 

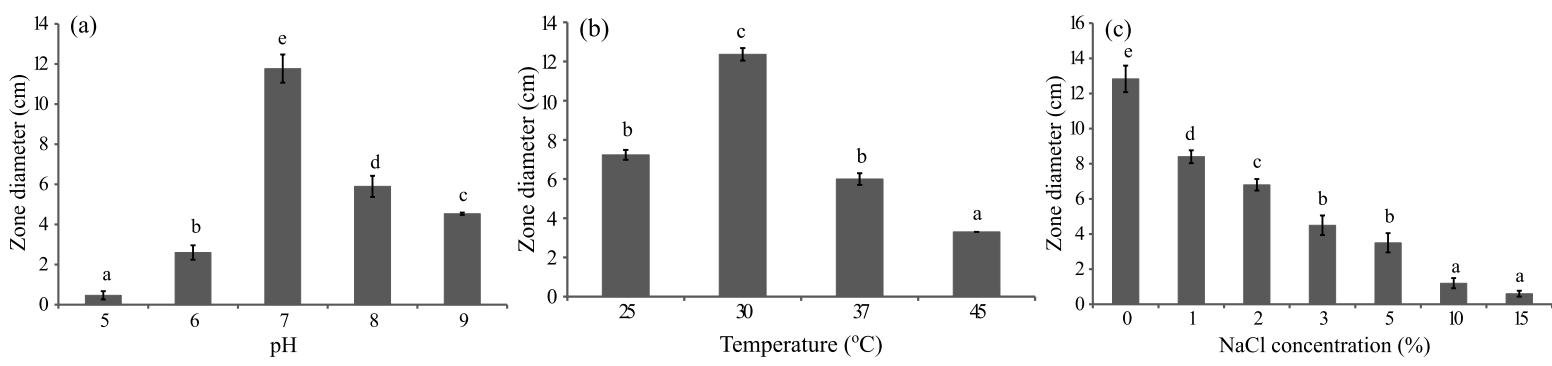

Fig. 4 Oil displacement activity of lipopeptide biosurfactant produced by B. subtilis SE1 grown in the medium at different (a) $\mathrm{pH}$, (b) temperature and (c) salinity. Letters indicate significant difference $(p<0.05)$ among treatments.

strates and physicochemical factors. Optimal environmental conditions for lipopeptide production of B. subtilis SE1 were growth in the medium with glucose and yeast extract (10 g/l) supplemented, at $30^{\circ} \mathrm{C}$, initial $\mathrm{pH} 7.0$ and no $\mathrm{NaCl}$ addition. At an optimal growth condition, lipopeptide biosurfactant produced by $B$. subtilis SE1 reached a maximum concentration of $66.00 \pm 1.54 \mathrm{mg} / \mathrm{l}$. The SE1 lipopeptide concentration in this study was comparatively lower than some previously reported values of $B$. atrophaeus $5-2 \mathrm{a}(0.77 \mathrm{~g} / \mathrm{l})$, B. velezensis KLP2016 (2.5 g/l) and B. subtilis B30 $(0.3-0.5 \mathrm{~g} / \mathrm{l})[8,20,29]$. It is worth noting that nutritional factors, particularly trace elements, play an important role in improving biosurfactant production because the elements are co-factors of enzymes responsible for the synthesis of biosurfactants. Gudiña et al [35] demonstrated that addition of metals (iron, manganese and magnesium) at optimal concentrations into culture broth resulted in a substantially increased production of biosurfactant biosynthesised by B. subtilis \#573 from about 1.3 up to $4.8 \mathrm{~g} / 1$. The close correlation between growth phases of the culture and biosurfactant productions has been reported in several lipopeptideproducing strains during the culture incubation. Rahman et al [36] observed that iturin A production by $B$. subtilis RB14 ceased on the fourth day of incubation when the nutrients were depleted and almost entire cells became spores. However, after germination of the spores through heat-activation and nutrient supplementation, the induced spores became metabolically active vegetative state, and the total production of iturin A was markedly increased up to $4000 \mathrm{~g} / \mathrm{l}$ at the end of fermentation. Therefore, an additional investigation related to enhancement of SE1 lipopeptide biosurfactant production should be further established. Lipopeptide SE1 showed a great reduction in surface tension from $72.27 \pm 0.01$ to $25.95 \pm 0.06 \mathrm{mN} / \mathrm{m}$ with increase in biosurfac-

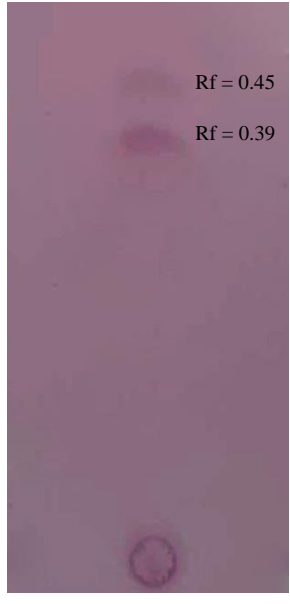

Fig. 5 layer chromatography profile of crude lipopeptide biosurfactant from $B$. subtilis SE1 sprayed with ninhydrin solution. Blue-purple spots indicated the presence of peptide moiety.

tant concentration up to CMC of $4.69 \pm 0.11 \mathrm{mg} / \mathrm{l}$. Similarly, other authors reported that Bacillus spp. are one of the most effective biosurfactant producers because their active substances reduce surface tension and have CMC values within our range $[8,14]$.

\section{Initial structural characterisation}

The TLC plate containing crude lipopeptide prepared from B. subtilis SE1 showed 2 compounds with Rf values of 0.39 and 0.45 , respectively (Fig. 5) when ninhydrin reagent was sprayed, indicating presence of peptide/amino acid residues. There was only 1 white band with $\mathrm{Rf}$ values of 0.83 observed when sprayed with water, confirming the presence of lipid moiety. These results confirmed the lipopeptide nature of biosurfactant produced by B. subtilis SE1. Similar results for other lipopeptide biosynthesised by Bacillus strains have been reported $[8,14,20]$. 

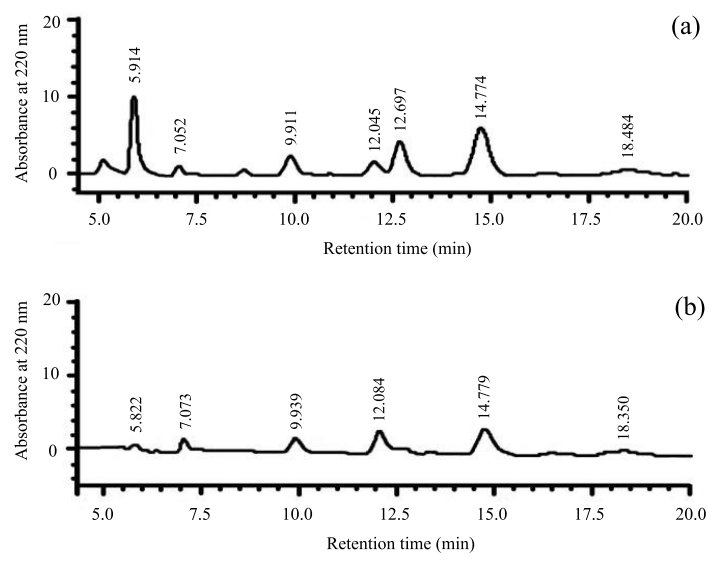

Fig. 6 HPLC profile of a reference surfactin at $100 \mathrm{mg} / \mathrm{ml}$ (a) and lipopeptide produced by B. subtilis SE1 (b) using an inersil ODS-C18 column.

Methanolic extract of biosurfactant produced by $B$. subtilis SE1 was compared to a commercially available surfactin using analytical reverse-phase HPLC. Patterns exhibited that lipopeptide SE1 was a complex mixture containing 6 components similar to those found in commercial surfactin (Fig. 6a). Four major compositions of lipopeptide SE1 were observed at retention time of 7.073, 9.939, 12.082 and $14.779 \mathrm{~min}$, and there were 2 minor components at retention time of 5.822 and $18.350 \mathrm{~min}$ (Fig. 6b). However, the component found in surfactin at retention time of $12.697 \mathrm{~min}$ was absent in lipopeptide SE1. Therefore, it was postulated that lipopeptide had most components similar to those found in surfactin, albeit different proportions. Further study for detailed structures and isoforms of lipopeptide SE1 is needed to ascertain this point.

Bacterial dynamics and metabolite fate during biodegradation in gasoline-contaminant soils

Bioaugmentation and biostimulation are environmentally friendly treatment technologies to enhance biodegradation of contaminated soil. There were significant increases in viable bacterial count in gasoline contaminated soil after a 7-day incubation with an associated increase in PRP value. In gasoline contaminated soil without SE1 addition (T1), viable bacterial count was relatively constant in the range of 5.56-5.60 log $\mathrm{CFU} / \mathrm{g}$ and was significantly lower than $(p<0.05)$ that observed in SE1 bioaugmented soil (Fig. 7). In gasoline contaminated soil with SE1 bioaugmentation (T2), viable bacterial count increased significantly $(p<$ 0.05 ) from $6.10 \pm 0.01 \log \mathrm{CFU} / \mathrm{g}$ at the begin-

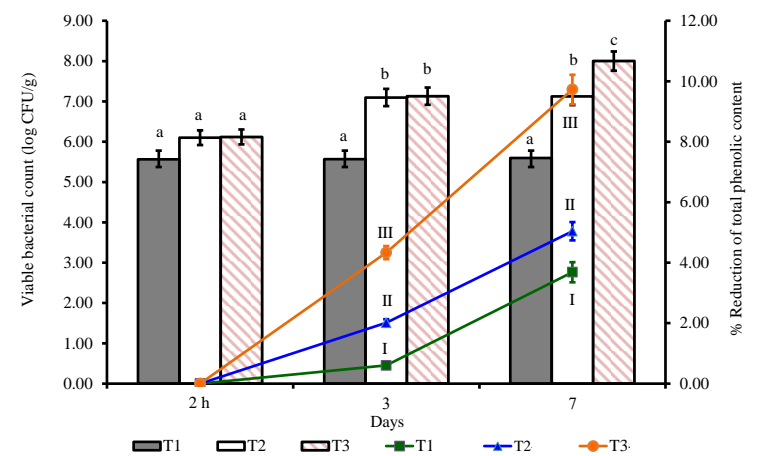

Fig. 7 Soil bacterial growth (bars) and percent reduction of total phenolic content (lines) in gasoline contaminated soil during a 7-day incubation. Letters indicate significant difference $(p<0.05)$ among treatments. Lines with roman numerals within same sampling period indicate significant difference $(p<0.05)$ among treatments.

ning of experiment to $7.12 \pm 0.05 \log \mathrm{CFU} / \mathrm{g}$ at 7 days post-incubation. Simultaneously, PRP value in T2 increased to $5.04 \pm 0.30 \%$, which was significantly different $(p<0.05)$ compared to that of T1 $(3.68 \pm 0.83 \%)$ at 7 days post-incubation (Fig. 7). This indicated that addition of SE1 in gasoline treated soil promoted the growth of bacterial consortium and PRP value. In general, coexistence of surface and emulsification activities of biosurfactant produced by bacteria facilitates hydrocarbon release and micellar solubilisation, which eventually enhances biodegradation kinetics dramatically $[8,10,11]$. The biosurfactant released by $B$. subtilis SE1 may have increased hydrocarbon mobility and bioavailability by increasing the surface area of insoluble hydrophobic substrates and enhancing contact between seeded or indigenous bacteria and water-insoluble hydrocarbon, thereby increasing bacterial growth and rate of bioremediation [10]. Mukherjee and Bordoloi [9] revealed $83 \%$ reduction of BTX contaminated in soil within 90 days of treatment with bacterial consortium containing B. subtilis DM-04 and Pseudomonas aeruginosa $\mathrm{M}$ and NM strains. Mangwani et al [24] also demonstrated an increase in phenolic intermediates during degradation of polycyclic aromatic hydrocarbons by Stenotrophomonas acidaminiphila strain NCW-702.

Although addition of $B$. subtilis SE1 alone aided bacterial growth and PRP value, combined $B$. subtilis SE1 and nutrients was strongly effective to accelerate bacterial access to the hydrocarbon and rate of biodegradation in gasoline contaminated soil. In 
our study, the highest viable bacterial count and PRP value of $8.00 \pm 0.04 \log \mathrm{CFU} / \mathrm{g}$ and $9.73 \pm 1.13 \%$ were seen in gasoline treated soil simultaneously bioaugmented with SE1 and the nutrients (T3) at day 7 of incubation, which were significantly $(p<$ 0.05) higher than those of T1 and T2 (Fig. 7). Supplementation of nutrients (glucose and yeast extract) may raise bioavailability and decrease surface resistance of hydrophobic substances through stimulation of $B$. subtilis SE1 growth and biosurfactant production as observed in optimisation experiment. Effect of nutrient supplementation on petroleum biodegradation varies widely and has been reported to both stimulate and inhibit hydrocarbon degradation dependent upon specific environmental conditions, chemical property of biosurfactant and its interaction with soil microorganisms. In a 12 week laboratory study on degradation of diesel oil in the light $\left(\mathrm{C}_{12}-\mathrm{C}_{23}\right)$ and heavy $\left(\mathrm{C}_{23}-\mathrm{C}_{40}\right)$ range by Bento et al [37], a reduction of $72 \%$ in the light fraction was produced using a combination technique between biostimulation and bioaugmentation. Abdulsalam and Omale [38] demonstrated that addition of nutrients only offered a lower degradation efficiency of used motor oil contaminated in soil, compared to administration of both nutrients and bacteria consortium during a 45-day incubation. Evaluation of biodegradation potential towards gasoline contaminated in soil environment of the SE1 strain using gas chromatography analysis should be further performed to ensure its biodegradation activity.

\section{CONCLUSION}

B. subtilis SE1 isolated from enriched petroleumpolluted soil was found to utilise gasoline as sole carbon source and produce lipopeptide biosurfactant. Lipopeptide production of $B$. subtilis SE1 was carried out in mineral salt medium with glucose and yeast extract $\left(10 \mathrm{~g} / \mathrm{l}\right.$ each) supplement at $30^{\circ} \mathrm{C}$, initial $\mathrm{pH} 7.0$ and no $\mathrm{NaCl}$ added. SE1 lipopeptide reduced the surface tension from $72.27 \pm 0.01$ to $25.95 \pm 0.06 \mathrm{mN} / \mathrm{m}$ with a critical micelle concentration of $4.69 \pm 0.11 \mathrm{mg} / 1$. In a biodegradation study, addition of the SE1 strain simultaneously with glucose and yeast extract supplement in gasolinecontaminated soils resulted in a significantly $(p<$ 0.05 ) increased viable bacterial count and PRP value during a 7-d incubation. This study suggests that lipopeptide-producing B. subtilis SE1 is a good candidate for application in the bioremediation of gasoline contaminated sites in Thailand. Future study focused on replacement of expensive nutri- ent sources in the culture media by cheaper agroindustrial wastes, by-products and other substances for SE1 lipopeptide production is required to reduce its production cost and increase its commercial competitiveness.

Acknowledgements: This study was financially supported by the National Research Council of Thailand (grant no. 88/2559, 119/2560 and 42/2561). We thank Mr. Khittipop Utila and Miss Saranya Uttakud for their technical assistance. We also acknowledge the staff of Department of Microbiology, Faculty of Science, Burapha University for providing experimental equipment and facilities.

\section{REFERENCES}

1. Mitra S, Roy P (2011) BTEX: a serious ground-water contaminant. Res J Environ Sci 5, 394-398.

2. Ismail W, Al-Rowaihi IS, Al-Humam AA, Hamza RY, El Nayal AM, Bououdina M (2013) Characterization of a lipopeptide biosurfactant produced by a crudeoil-emulsifying Bacillus sp. I-15. Int Biodeterior Biodegrad 84, 168-178.

3. Adams GO, Fufeyin PT, Okoro SE, Ehinomen I (2015) Bioremediation, biostimulation and bioaugmention: a review. Int $J$ Environ Bioremediat Biodegrad 3, 28-39.

4. Adams GO, Fufeyin PT, Ehinomen I (2014) Bioremediation of spent oil contaminated soils using poultry litter. Res J Eng Appl Sci 3, 124-130.

5. IARC (2013) Diesel and petrol engine exhausts and some nitroarenes. In: IARC Monographs on the Evaluation of the Carcinogenic Risk of Chemicals to Humans, vol 105, International Agency for Research on Cancer, Lyon, France.

6. IARC (2000) Some industrial chemicals. In: IARC Monographs on the Evaluation of the Carcinogenic Risk of Chemicals to Humans, vol 77, International Agency for Research on Cancer, Lyon, France.

7. Plaza G, Chojniak J, Rudnicka K, Paraszkiewicz K, Bernat P (2015) Detection of biosurfactants in Bacillus species: genes and products identification. $J$ Appl Microbiol 119, 1023-1034.

8. Zhang J, Xue Q, Gao H, Lai H, Wang P (2016) Production of lipopeptide biosurfactants by Bacillus atrophaeus $5-2 \mathrm{a}$ and their potential use in microbial enhanced oil recovery. Microb Cell Fact 15, ID 168.

9. Mukherjee AK, Bordoloi NK (2012) Biodegradation of benzene, toluene, and xylene (BTX) in liquid culture and in soil by Bacillus subtilis and Pseudomonas aeruginosa strains and a formulated bacterial consortium. Environ Sci Pollut Res 19, 3380-3388.

10. Ron EZ, Rosenberg E (2002) Biosurfactants and oil bioremediation. Curr Opin Biotechnol 13, 249-252.

11. Bezza FA, Chirwa EMN (2015) Production and applications of lipopeptide biosurfactant for bioremedia- 
tion and oil recovery by Bacillus subtilis CN2. Biochem Eng $J$ 101, 168-178.

12. Pereira JFB, Gudiña EJ, Costa R, Vitorino R, Teixeira JA, Coutinho JAP, Rodrigues LR (2013) Optimization and characterization of biosurfactant production by Bacillus subtilis isolates towards microbial enhanced oil recovery applications. Fuel 111, 259-268.

13. Ramadan EM, Kheiralla ZM, Fouad MA, El Tayeb TS, Gomaa EZ (2011) Optimization of biosurfactant production by Bacillus licheniformis isolated from oil contaminated Egyptian soil. Egypt J Microbiol 46, $1-20$.

14. Jha SS, Joshi SJ, Geetha SJ (2016) Lipopeptide production by Bacillus subtilis R1 and its possible applications. Braz J Microbiol 47, 955-964.

15. Jaysree RC, Basu S, Singh PP, Ghosal T, Patra PA, Keerthi Y, Rajendran N (2011) Isolation of biosurfactant producing bacteria from environmental samples. Pharmacology Online 3, 1427-1433.

16. Howland JL, Garfield A (1993) Enrichment culture technique can be used to introduce variety into a biochemical laboratory course. Biochem Educ 21, 218.

17. Cooper DG, Goldenberg BG (1987) Surface active agents from two Bacillus species. Appl Environ Microbiol 53, 224-229.

18. Dagorn A, et al (2013) Effect of GABA, a bacterial metabolite, on Pseudomonas fluorescens surface properties and cytotoxicity. Int J Mol Sci 14, 12186-12204.

19. Sambrook J, Fritsch EF, Maniatis T (1989) Molecular Cloning: a Laboratory Manual, 2nd edn, Cold Spring Harbor Laboratory Press, New York.

20. Meena KR, Tandon T, Sharma A, Kanwar SS (2018) Lipopeptide antibiotic production by Bacillus velezensis KLP2016. J Appl Pharm Sci 8, 91-98.

21. Ayed HB et al (2014) Identification and biochemical characteristics of lipopeptides from Bacillus mojavensis A21. Process Biochem 49, 1699-1707.

22. Bordoloi NK, Konwar BK (2008) Microbial surfactant-enhanced mineral oil recovery under laboratory conditions. Colloids Surf B 63, 73-82.

23. Okoh AI (2013) Biodegradation of bonny light crude oil in soil microcosm by some bacterial strains isolated from crude oil flow stations saver pits in Nigeria. Afr J Biotechnol 1, 45-48.

24. Mangwani N, Shukla SK, Kumari S, Rao TS, Das S (2014) Characterization of Stenotrophomonas acidaminiphila NCW-702 biofilm for implication in the degradation of polycyclic aromatic hydrocarbons. $J$ Appl Microbiol 117, 1012-1024.

25. Zar JH (1996) Biostatistical Analysis, 3rd edn, Prentice Hall, New Jersey.

26. Thavasi R, Sharma S, Jayalakshmi S (2011) Evaluation of screening methods for the isolation of bio- surfactant producing marine bacteria. $J$ Pet Environ Biotechnol S1, ID 001.

27. Liu JH, Maity JP, Jean JS, Chen CY, Chen CC, Ho SY (2010) Biodegradation of benzene by pure and mixed cultures of Bacillus spp. World J Microbiol Biotechnol 26, 1557-1567.

28. Wang L, Qiao N, San F, Shao Z (2008) Isolation, gene detection and solvent tolerance of benzene, toluene and xylene degrading bacteria from near shore surface water and Pacific Ocean sediment. Extremophiles 12, 335-342.

29. Al-Wahaibi Y, Joshi S, Al-Bahry S, Elshafie A, AlBemani A, Shibulal B (2014) Biosurfactant production by Bacillus subtilis B30 and its application in enhancing oil recovery. Colloids Surf B 114, 324-333.

30. Parthipan P, Preetham E, Machuca LL, Rahman PKSM, Murugan K, Rajasekar A (2017) Biosurfactant and degradative enzymes mediated crude oil degradation by bacterium Bacillus subtilis A1. Front Microbiol 8, ID 193.

31. Ghribi D, Ellouze-Chaabouni S (2011) Enhancement of Bacillus subtilis lipopeptide biosurfactants production through optimization of medium composition and adequate control of aeration. Biotechnol Res Int 2011, ID 653654.

32. Davis DA, Lynch HC, Varley J (1999) The production of surfactin in batch culture by Bacillus subtilis ATCC 21332 is strongly influenced by the conditions of nitrogen metabolism. Enzyme Microb Technol 25, 322-329.

33. Ohno A, Ano T, Shoda M (1995) Effect of temperature on production of lipopeptide antibiotics, iturin A and surfactin by a dual producer, Bacillus subtilis RB14, in solid-state fermentation. J Ferment Bioeng 80, 517-519.

34. Tabatabaee A, Assadi MM, Noohi AA, Sajadian VA (2005) Isolation of biosurfactant producing bacteria from oil reservoirs. Iran J Env Health Sci Eng 2, 6-12.

35. Gudiña E, Fernandes EC, Rodrigues AI, Teixeira JA, Rodrigues LR (2015) Biosurfactant production by Bacillus subtilis using corn steep liquor as culture medium. Front Microbiol 6, ID 59

36. Rahman MS, Ano T, Shoda M (2006) Second stage production of iturin A by induced germination of Bacillus subtilis RB14. J Biotechnol 125, 513-515.

37. Bento FM, Camargo FAO, Okeke BC, Frankenberger WT (2005) Comparative bioremediation of soils contaminated with diesel oil by natural attenuation, biostimulation and bioaugmentation. Bioresour Technol 96, 1049-1055.

38. Abdulsalam S, Omale AB (2009) Comparison of biostimulation and bioaugmentation techniques for the remediation of used motor oil contaminated soil. Braz Arch Biol Technol 52, 747-754. 